\title{
Analysis of Water Mist Suppression with Foam Additive in Wind Generator
}

\author{
Chen-Wei Chiu ${ }^{1}$, Yin-Tsz Lin ${ }^{1}$ and Yi-Liang Shu ${ }^{2}$ \\ 1. Department of Fire Safety, National Taiwan Police College, Taipei, Taiwan 11696, ROC \\ 2. Department of Safety Health and Environmental Engineering, Central Taiwan University of Sciences and Technology, Taichung, \\ Taiwan 40601, ROC
}

\begin{abstract}
The study adopted a 20-foot long container to simulate the situation inside a turbine cabin. Water mist sprays were installed internally and used to perform fire extinguishing tests. Under these different scenarios, several operating factors were adjusted with the results of each adjustment subsequently measured. The operating factors studied included: operating pressures, foam concentrations, cabin opening issues, and obstacles. Each of the factors was compared with the others so as to find out which combinations would be most suitable for a water mist spray system installed inside a wind turbine cabin. The presence of obstructions hinders the direct impact of the mist spray on the fire source and in average an additional 2 to 3 minutes is required to put out the fire. This study found that the effect of the foam-water ratio is linear. Regardless of the scenario, the optimum mixture ratio is $3 \%$. The line graph shows that the most unsuitable aqueous film-forming mixture ratio is $6 \%$. This experiment found that the main fire extinguishing mechanism of water mist spray is the cooling of a large area via water droplets. This system is very effective in bringing down the temperature. The addition of foam in water mist spray, however, impaired the effectiveness of the cooling effect although the fire control mechanism via emulsification markedly reduced the time required to put out the fire. The increase in foam magnification will considerably enhance the fire extinguishing efficiency.
\end{abstract}

Key words: Turbine cabins, water mist, water droplets, foam magnification, fire extinguishing efficiency.

\section{Introduction}

To reduce carbon dioxide emissions, it is very important to develop wind power and other renewable energies. With increases in the costs of fossil fuels and the gradual decrease in energy resources, there is a need to search for and develop alternative energies. Wind, hydro, solar, and wave energies are the new generation of renewable energy sources and will gradually replace and reduce the use of nuclear energy, coal energy, and natural gas in electricity generation. From an economic point of view, wind energy is potentially more competitive than other renewable energies and is booming rapidly. Wind energy is safe and is beneficial for both economic development and environmental protection. At the current stage, the

\footnotetext{
Corresponding author: Chen-Wei Chiu, Dr., main research field: fire protection engineering. E-mail: eswin.wei@gmail.com.
}

more developed and commonly used renewable energies are hydro energy, wind energy, and solar energy. The generation of electricity with wind power is completely dependent on the natural resource of wind, such that the burning and consumption of fuel or coal is absolutely unnecessary. The wind power generation process does not lead to carbon dioxide emissions or secondary pollution. Other than noise, it produces minimal detrimental impacts on the environment. Therefore, countries around the world are actively developing wind energy, and the practical application of wind energy in electricity generation is already producing remarkable results.

In NFPA750 [1], water mist is defined as spray in which $99 \%$ of spray droplets, by flow-weighted cumulative distribution, have diameters $<1,000 \mathrm{~mm}$ as the minimum design operating pressure of water mist nozzles. Due to the large surface-to-volume ratio and 
long suspension time, water mist has very effective fire extinguishing characteristics. The dominant mechanisms for fire suppression with water mist are flame cooling, oxygen displacement, radiant attenuation, dilution of flammable vapors, and direct impingement wetting and cooling of combustible materials [2]. Mawhinney [3] used a twin-fluid nozzle to generate a fine spray to extinguish liquid pool fires. It was Mawhinney who found that spraying downward directly at the flame is the most effective means of extinguishing a fire. Obstructions in the spray path alleviate the spray's momentum and the amount of water suspended in the air as mist, resulting in reduced capacity to extinguish a fire.

Richard et al. [4] conducted an experimental study of the effects of water mist on a small heptane pool fire. The obtained map of temperature and extinction coefficient due to soot and water droplets provided new information about the flame structure. They showed that extinguishing a fire with water mist is accomplished by rapid and total clearance of water, rather than by a reduction in burning rate. Mawhinney and Solomon [5] utilized a twin-fluid nozzle to generate a fine spray to extinguish liquid pool fires. Mawhinney demonstrated that spraying downward directly at the flames is the most effective means of extinguishing a fire. Obstructions in the spray path reduce spray momentum and the amount of water suspended in air as mist, resulting in reduced ability to extinguish a fire. Zhou et al. [6] conducted a phenomenological study of the effect of MC (multi-composition) additives on water-mist fire-extinguishing efficiency based on ethanol, diesel, and wood fires. Zhou et al. found that adding a small quantity of MC additives into water-mist significantly improves the performance of water-mist systems in suppressing fires. However, when too much of MC additives are utilized, fire-extinguishing efficiency declines. Water in the form of mist has recently become an important area of study as a replacement [7]. Application of water mist offers several advantages, such as no toxicity, no corrosion, no adverse environmental effects, and ubiquity [8]. To further enhance the fire-extinguishing efficiency, many kinds of water mist additives have been developed in the past years, but most of additives have serious shortcomings in applications [9-15]. For example, the inorganic metal additives cause corrosion to equipment. The organic additives are toxic to human beings and could not improve the fire-extinguishing efficiency of water mist greatly [16].

To improve the fire suppression performance of water mist, many kinds of chemical additives were developed, which could be classified into those acting on the fire mainly through physical effect and those through chemical reactions. The additives which govern fires by physical mechanisms are some surfactants. Water with surfactants dissolved usually has decreased surface tension, which can increase the wetted area by deeper penetration, or form a foam blanket over the fire to give oxygen starvation [17]. Chemical agents could decompose in the combustion region to generate highly reactive species to terminate free radicals [18]. Metal salts, such as alkali halide, alkali hydroxide, and alkali oxysalt are most widely used additives to improve the chemical fire suppression ability of water mist. In some cases, these two kinds of additives are utilized together to further boost the efficacy of water mist in fire suppression. For example, a multi-component additive named MC including surfactants, alkali salts, and organic solvent was prepared by Zhou [19]. Water mist with MC additive demonstrated better fire suppression performance in extinguishing liquid fuel fires than those containing only metallic compounds or film forming surfactant [20]. Although additives mentioned above could improve the performance of water mist in fire suppression, they might erode precision equipment and cleaning up the additive residue after a fire remains problems. Furthermore, water mist with additives might be condensed on the 
exposed electrical equipment to render short circuiting [21]. Currently, it is still challenging to explore new clean and efficient additives to water mist.

This study explored the fire protection efficiency of water mist spray and foam-treated water mist spray in large scale wind power generator. The research goals as follows:

- The effect of operating pressure on water mist spray;

- The effect of obstructions on water mist spray;

- The effect of foam net on foam-treated water mist spray;

- The effect of foam-water ratio on the foam-treated water mist spray;

- The effect of operating pressure on the foam-treated water mist spray;

- Water mist spray and foam-treated water mist spray.

\section{Experimental Instruments and Devices}

\subsection{Descriptions of the Experimental Instruments and} Devices

This study aimed to test the fire extinguishing effectiveness of water mist spray and foam-treated water mist spray in case of fire in a large-scale wind turbine cabin. Due to the size of the large scale wind turbine cabin, it was impossible to build an actual size simulation model. Therefore, a 20 -foot container measuring $6.05 \mathrm{~m}$ long $\times 2.43 \mathrm{~m}$ wide $\times 2.5 \mathrm{~m}$ tall, which was approximately one third of the original size,

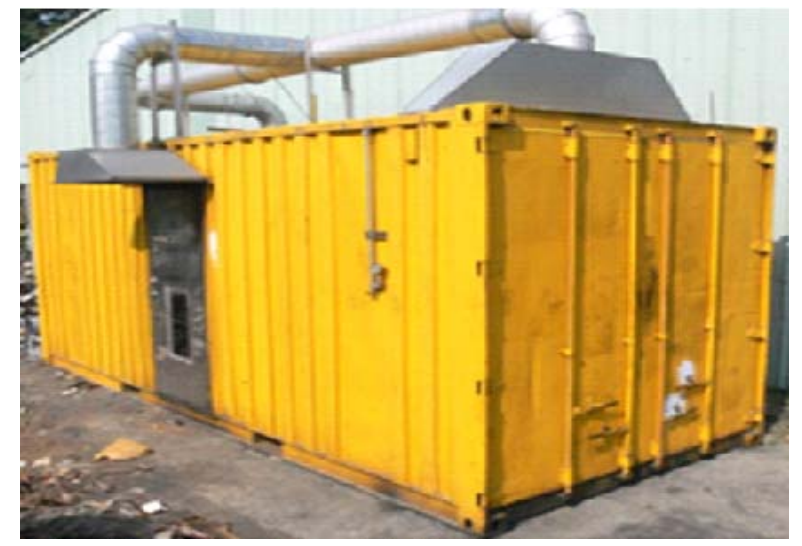

was used to simulate the conditions of a cabin in a wind power generator (Fig. 1).

\subsection{Experimental Method}

The experiment was carried out with an oil basin conforming to B2 grade of the CNS specification. Simulation scenarios range from 1 to 24 . The fixed parameters were the positioning of the fire source in the center of the container and the use of 2 spray nozzles. The varying parameters included the operating pressure of the high-pressure pump ranging from $100 \mathrm{bar}, 70$ to $40 \mathrm{bar}$, the presence of opening at the simulation site, the addition of obstructions, and the concentration of foam. The extinguishment of fire with water mist was carried out according to the above procedure to assess its fire extinguishing effectiveness and the time required to put out the fire. Temperatures were recorded and the entire process was video recorded.

\subsection{Arrangement of Devices}

The ceiling inside the container was installed with the water mist spray nozzles (Fig. 2) for fire extinguishment. The flow rate of each spray nozzle was 13.5 LPM and the nozzle was connected to a high-pressure pump via a high-pressure water pipe.

Pressurized, water flows through the water pipe and was released via the water mist spray nozzle for fire extinguishment test of water mist sprays. Twelve K-type thermocouples were installed inside the container

Fig. 1 Container configuration of the wind power generator cabin.

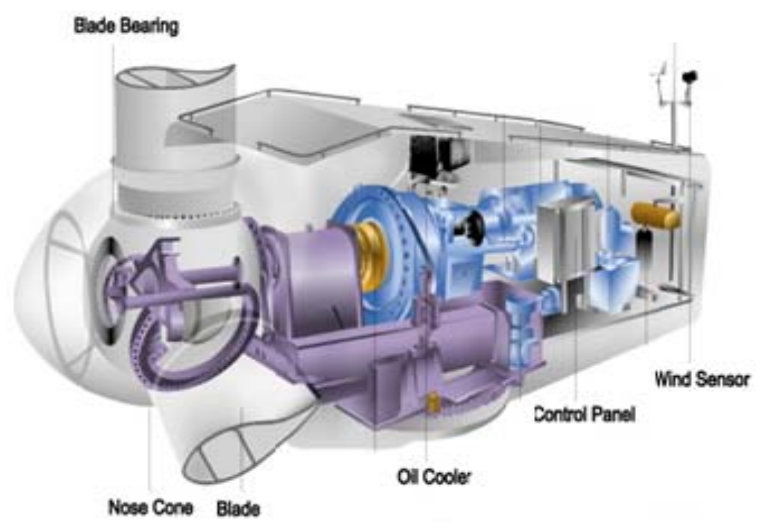



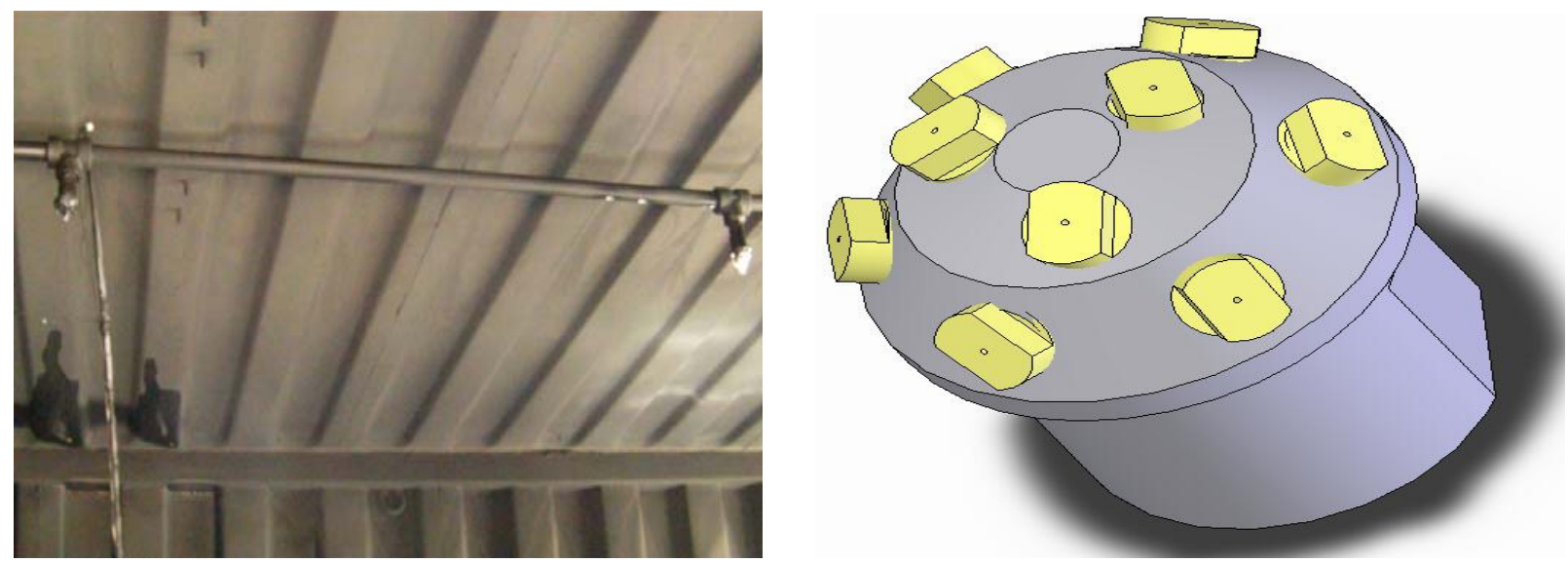

Fig. 2 The self-made mist spray nozzles design and installation on the ceiling of the container.

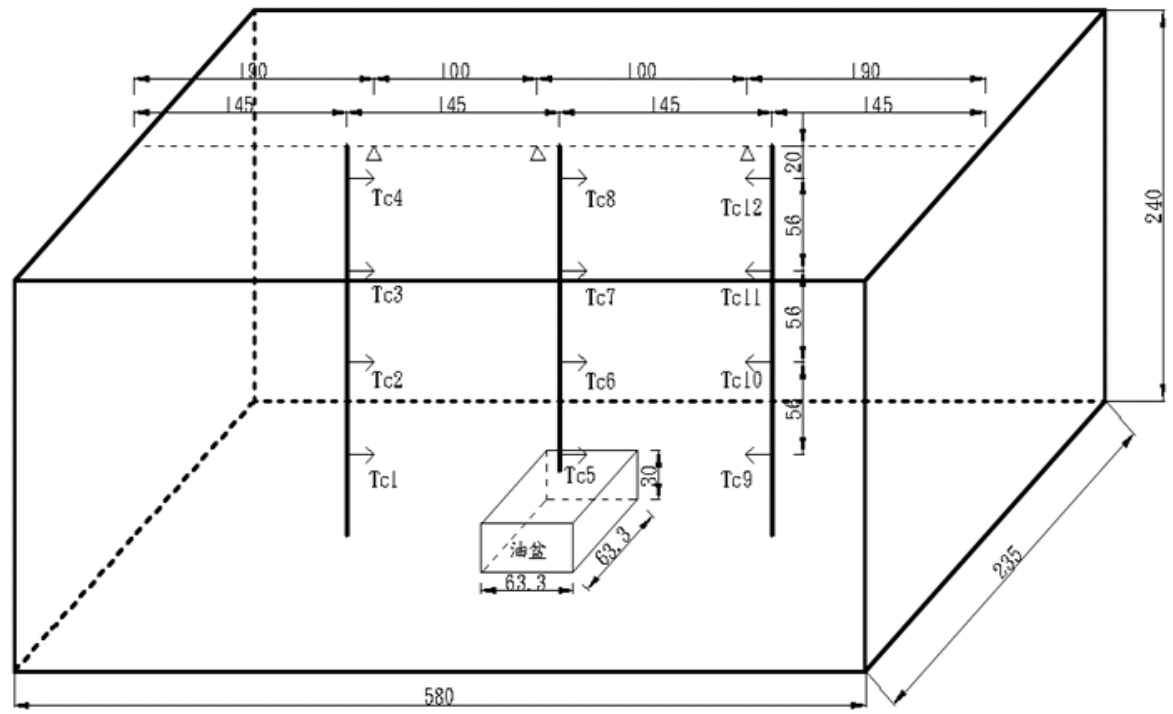

I Screw $\triangle$ Spray nozzle $\rightarrow$ Thermocouple $\quad$ (Unit: cm)

Fig. 3 The arrangement of thermocouples, spray nozzles, and oil basin at wind turbine container.

to measure the temperature inside the container. The readings were then output to a data capture device. The positions of the spray nozzle, fire source, and thermocouples were shown in Figs. 3 and 4.

The fire extinguishing foam net with foam agent used in this study was the Profilm 3 aqueous film-forming liquid foam from PROFOAM. The undiluted aqueous foam was directly added into the water source and the concentration of the aqueous foam in water was adjusted to $3 \%$ (Fig. 5).

\subsection{Asymmetric Uncertainties of Thermocouple}

All of the data from experimental results may not be equally good to adopt. Their accuracy should be confirmed before the experimental results were analyzed. Uncertainty analysis (or error analysis) was a procedure used to quantify data validity and accuracy. Errors always were present in experimental measuring; they can be categorized into the fixed (systematic) error and random (non-repeatability) error, respectively [7]. Fixed error was the same for each reading and can be removed by proper calibration and correction. Random error was different for every reading and hence cannot be removed. The objective of uncertainty analysis was to estimate the probable random error in experimental results. 


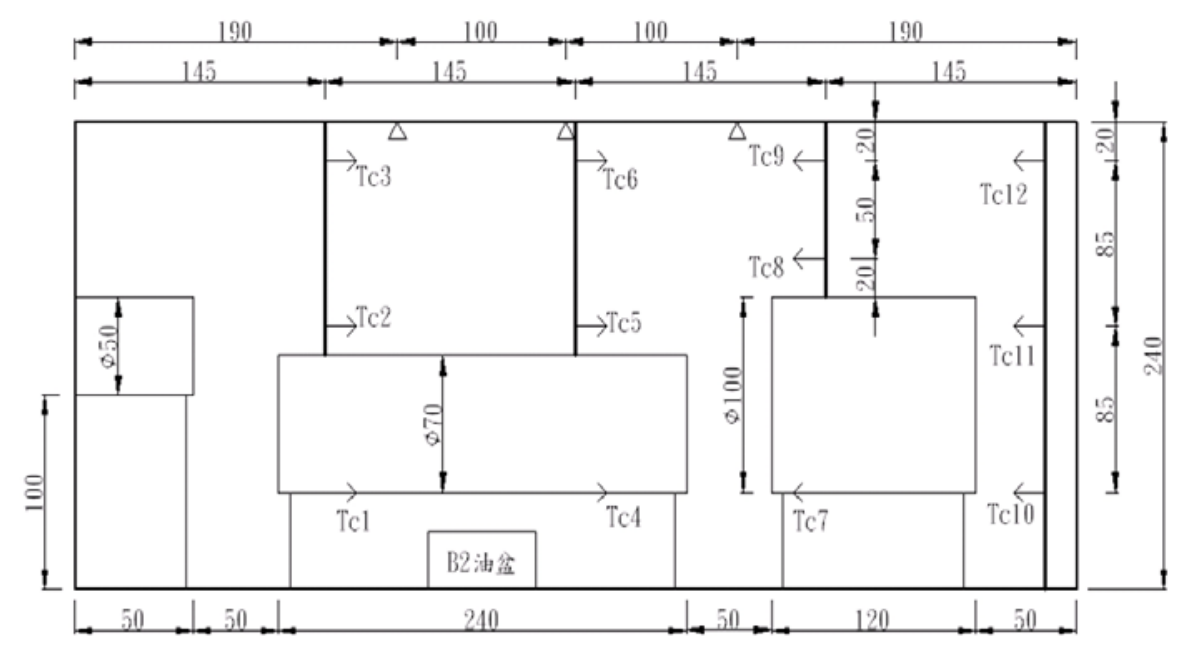

\section{| Screw $\triangle$ Spray nozzle $\rightarrow$ Thermocouple (Unit: $\mathrm{cm}$ )}

Fig. 4 Schematic configuration of the sheltered fire source with the thermocouple, nozzle and oil pan.
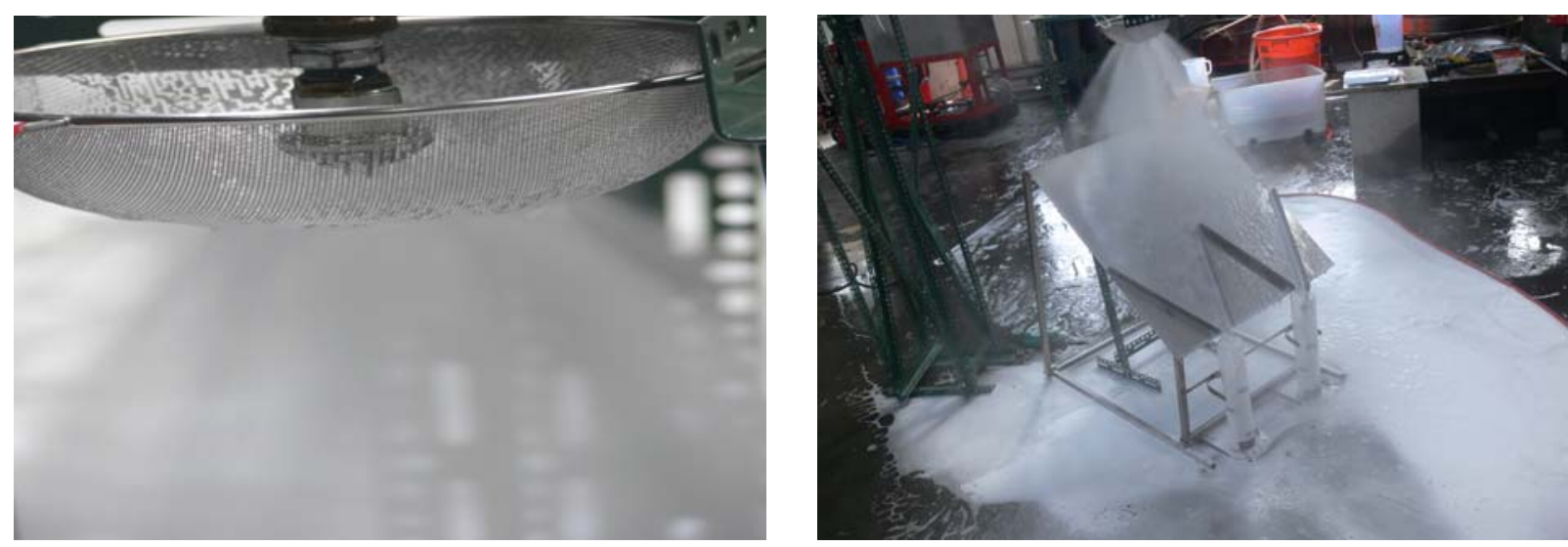

Fig. 5 The operation discharge test of the mist spray nozzles with foam net.

The temperatures in the fire room tests were measured by a $1 \mathrm{~mm}$ diameter K-type, whose signals were sent to a PC-record (Ethernet). The accuracy of the thermocouple itself without coating was $\pm 0.2 \%$. Due to the effects of conduction, convection, and radiation, it was worthwhile to check the correctness of gas temperature measured by such K-type thermocouple. By means of an application of energy balance, i.e.,

Energy in $=$ Energy out, or Convection to the junction of thermocouple $=$ Radiation from the junction of thermocouple + conduction loss from the probe.

Because of the fine thermocouple $(1 \mathrm{~mm})$, the conduction term can be negligible. Then, the steady-state energy equation can be rewritten as follows [8]:

$$
\frac{4 h}{D_{w}}\left(T_{g}-T_{t}\right)-\frac{4 \sigma}{D_{w}}\left(\varepsilon T_{t}^{4}-\varphi T_{w}^{4}\right)=0
$$

where

$T_{\mathrm{t}}=$ flame temperature $\left({ }^{\circ} \mathrm{C}\right)$

$T_{\mathrm{g}}=$ true gas temperature $\left({ }^{\circ} \mathrm{C}\right)$

$T_{\mathrm{w}}=$ wall temperature $\left({ }^{\circ} \mathrm{C}\right)$

$\varepsilon=$ emissivity of the thermocouple

$\sigma=$ Stefan-Boltzmann constant $\left(5.67 \times 10^{-8}\right.$, $\mathrm{W} / \mathrm{m}^{2} / \mathrm{K}^{4}$ )

$h=$ convective heat transfer coefficient at thermocouple wire surface $\left(\mathrm{W} / \mathrm{m}^{2} / \mathrm{K}\right)[8]$ 
In practice, the flame temperature was usually above $1000{ }^{\circ} \mathrm{C}$, so the absorption term, $\varphi T_{w}^{4}$, from the relatively low wall temperature can be removed from Eq. (1). According to Eq. (1), the expression of correlation can be given as Eq. (2):

$$
T_{g}=T_{t}+\frac{\varepsilon \sigma T_{t}{ }^{4}}{h}
$$

Now, the analysis method of uncertainty can be used to obtain the uncertainty in the flame temperature from the correlation associated with $h, T_{\mathrm{t}}$, and $\varepsilon$ [9]. By means of the uncertainty calculation, the maximum uncertainty value was found to be $65{ }^{\circ} \mathrm{C}$ when the gas temperature was up to $1000{ }^{\circ} \mathrm{C}$. On the other hand, it had a minimum uncertainty value as $0.47{ }^{\circ} \mathrm{C}$ when the gas temperature was $25{ }^{\circ} \mathrm{C}$. Consequently, the percentage of uncertainty value varied from 0.12 to $7 \%$ as the corresponding value was altered from 0.47 to $65{ }^{\circ} \mathrm{C}$.

\section{Results and Discussion}

\subsection{Water Mist Spray Tests}

\subsubsection{Fire Test under the Pressure of $100 \mathrm{~kg}_{\mathrm{f}} / \mathrm{cm}^{2}$}

The efficiency of the water mist spray fire protection system was evaluated under the operating pressure of $100 \mathrm{kgf} / \mathrm{cm}^{2}$ and several fixed parameters such as the use of B2 oil basin, the positioning of the fire source in the center of the container, no foam additives, and the flow rate of each spray nozzle at 13.5 LPM. The varying test parameters included the presence or absence of obstructions and opening in the simulation site (Table 1).

The test results for experiments conducted under the pressure of $100 \mathrm{kgf} / \mathrm{cm}^{2}$ are listed in Table 2. In the scenario 1 experiment, B2 oil basin was placed in the center of the container, the simulation site has no opening or obstructions, and the fire was extinguished using 2 water mist spray nozzles. The water mist sprays were activated manually to put out the fire after the fire had burnt for about $60 \pm 2 \mathrm{~s}$. A total of 2 tests were conducted and the highest temperatures recorded were 771 and $756{ }^{\circ} \mathrm{C}$, respectively. During the process of putting out the fire, only the temperature at the upper part of the fire source was relatively high. The time required to put out the fire was 134 and $130 \mathrm{~s}$, respectively. The temperature at the fire scene dropped to about $45^{\circ} \mathrm{C}$ after the fire had been put out.

3.1.2 Fire Test under the Pressure of $70 \mathrm{kgf} / \mathrm{cm}^{2}$

The efficiency of the water mist spray fire protection system was evaluated under the operating pressure of $70 \mathrm{~kg}_{\mathrm{f}} / \mathrm{cm}^{2}$ and several fixed parameters such as the use of B2 oil basin, the positioning of the fire source in the center of the container, no foam additives, and the flow rate of each spray nozzle at 13.5 LPM. The varying parameters included the presence or absence of obstructions and opening in the simulation site (Table 1).

The test results for experiments conducted under

Table 1 Water mist spray tests with unsheltered fire source under different scenarios.

\begin{tabular}{llllll}
\hline & Number of spray nozzles & Operating pressure & Opening & Obstruction & Foam additive \\
\hline Scenario 1 & 2 & $100 \mathrm{bar}$ & Nil & Nil & $\times$ \\
Scenario 2 & 2 & $100 \mathrm{bar}$ & Yes & Nil & $\times$ \\
Scenario 3 & 2 & $100 \mathrm{bar}$ & Nil & Yes & $\times$ \\
Scenario 4 & 2 & $100 \mathrm{bar}$ & Yes & Yes & $\times$ \\
Scenario 5 & 2 & $70 \mathrm{bar}$ & Nil & Nil & $\times$ \\
Scenario 6 & 2 & $70 \mathrm{bar}$ & Yes & Nil & $\times$ \\
Scenario 7 & 2 & $70 \mathrm{bar}$ & Nil & Yes & $\times$ \\
Scenario 8 & 2 & $70 \mathrm{bar}$ & Yes & Yes & $\times$ \\
Scenario 9 & 2 & $40 \mathrm{bar}$ & Nil & Nil & $\times$ \\
Scenario 10 & 2 & $40 \mathrm{bar}$ & Yes & Nil & $\times$ \\
Scenario 11 & 2 & $40 \mathrm{bar}$ & Yil & Yes & $\times$ \\
Scenario 12 & 2 & $40 \mathrm{bar}$ & & Yes & $\times$ \\
\hline
\end{tabular}


Table 2 Fire test under the pressure of $100 \mathrm{kgf} / \mathrm{cm}^{2}$ and different scenarios.

\begin{tabular}{lllll}
\hline Situation model & \multicolumn{1}{l}{ Highest temperature $\left({ }^{\circ} \mathrm{C}\right)$} & Temperature after fire has been put out $\left({ }^{\circ} \mathrm{C}\right)$ & Time required to put out fire $\left({ }^{\circ} \mathrm{C}\right)$ \\
\hline \multirow{2}{*}{ Scenario 1} & 1 & 771 & 46 & 134 \\
& 2 & 756 & 45 & 130 \\
\hline \multirow{2}{*}{ Scenario 2} & 1 & 841 & 47 & 153 \\
& 2 & 788 & 46 & 151 \\
\hline \multirow{2}{*}{ Scenario 3} & 1 & 836 & 41 & 125 \\
& 2 & 733 & 42 & 111 \\
\hline \multirow{2}{*}{ Scenario 4} & 1 & 797 & 40 & 157 \\
& 2 & 777 & 32 & 165 \\
\hline
\end{tabular}

Table 3 Fire Test under the pressure of $70 \mathrm{kgf} / \mathrm{cm}^{2}$ and different scenarios.

\begin{tabular}{lllll}
\hline Situation model & \multicolumn{1}{c}{ Highest temperature $\left({ }^{\circ} \mathrm{C}\right)$} & Temperature after fire has been put out $\left({ }^{\circ} \mathrm{C}\right)$ & Time required to put out fire $\left({ }^{\circ} \mathrm{C}\right)$ \\
\hline \multirow{2}{*}{ Scenario 5} & 1 & 782 & 47 & 157 \\
& 2 & 795 & 46 & 144 \\
\hline \multirow{2}{*}{ Scenario 6} & 1 & 793 & 47 & 197 \\
& 2 & 786 & 45 & 200 \\
\hline \multirow{2}{*}{ Scenario 7 } & 1 & 784 & 43 & 184 \\
& 2 & 772 & 42 & 171 \\
\hline \multirow{2}{*}{ Scenario 8} & 1 & 821 & 47 & 169 \\
& 2 & 715 & 45 & 161 \\
\hline
\end{tabular}

the pressure of $70 \mathrm{kgf} / \mathrm{cm}^{2}$ are given in Table 3 . In the scenario 5 experiment, B2 oil basin was placed in the center of the container, the simulation site had no opening or obstructions, and the fire was extinguished using 2 water mist spray nozzles. The water mist sprays were kicked off manually to put out the fire after the fire has burnt for about $60 \pm 2 \mathrm{~s}$. A total of 2 tests were executed and the highest temperatures recorded were 782 and $795{ }^{\circ} \mathrm{C}$, respectively. During the process of putting out the fire, only the temperature at the upper part of the fire source was relatively high. The time required to put out the fire were 157 and $144 \mathrm{~s}$, respectively. The temperature at the fire scene alleviated to about $46{ }^{\circ} \mathrm{C}$ after the fire had been gulled.

\subsubsection{Fire Test under the Pressure of $40 \mathrm{kgf} / \mathrm{cm}^{2}$}

The efficiency of the water mist spray fire protection system was evaluated under the operating pressure of $40 \mathrm{~kg}_{\mathrm{f}} / \mathrm{cm}^{2}$ and several fixed parameters such as the use of B2 oil basin, the positioning of the fire source in the center of the container, no foam additives, and the flow rate of each spray nozzle at 13.5 LPM. The varying parameters included the presence or absence of obstructions and opening in the simulation site (Table 1).

The test results for experiments conducted under the pressure of $40 \mathrm{kgf} / \mathrm{cm}^{2}$ were displayed in Table 4 . In the scenario 9 experiment, B2 oil basin was placed in the center of the container, the simulation site had no opening or obstructions, and the fire was extinguished using 2 water mist spray nozzles. The water mist sprays were activated manually to put out the fire after the fire had burnt for about $60 \pm 2 \mathrm{~s}$. A total of 2 tests were conducted and the highest temperatures recorded were 892 and $857{ }^{\circ} \mathrm{C}$, respectively. During the process of putting out the fire, only the temperature at the upper part of the fire source was relatively high. The time required to put out the fire was 156 and $172 \mathrm{~s}$, respectively. The temperature at the fire scene decreased to about $46{ }^{\circ} \mathrm{C}$ after the fire had been put out.

\subsection{Foam-Treated Water Mist Spray Test}

\subsubsection{Fire Test with Foam Ratio of 3\%}

The efficiency of the $3 \%$ foam-treated water mist spray fire protection system was evaluated under 
several fixed parameters, such as the use of B2 oil basin, the positioning of the fire source in the center of the container, the operating pressure of $100 \mathrm{kgf} / \mathrm{cm}^{2}$, and the flow rate of each spray nozzle at 13.5 LPM. The varying parameters included the presence or absence of foam net and opening in the simulation site (Table 5).

The test results for experiments conducted with foam ratio of $3 \%$ were listed in Table 6 . In the scenario 13 experiment (Fig. 6), in the experiment, B2 oil basin is placed in the center of the container, the simulation site had no opening, foam net was not installed, and the fire was extinguished using 2 water mist spray nozzles. The water mist sprays were activated manually to put out the fire after the fire had burnt for about $60 \pm 2 \mathrm{~s}$. A total of 2 tests were conducted and the highest temperatures recorded were 835 and $846{ }^{\circ} \mathrm{C}$, respectively. During the process of putting out the fire, only the temperature at the upper part of the fire source was relatively high. The time required to put out the fire were 76 and $99 \mathrm{~s}$, respectively. The temperature at the fire scene lessened

Table 4 Fire test under the pressure of $40 \mathrm{kgf} / \mathrm{cm}^{2}$ and different scenarios.

\begin{tabular}{lllll}
\hline Situation model & \multicolumn{1}{c}{ Highest temperature $\left({ }^{\circ} \mathrm{C}\right)$} & Temperature after fire has been put out $\left({ }^{\circ} \mathrm{C}\right)$ & Time required to put out fire $\left({ }^{\circ} \mathrm{C}\right)$ \\
\hline \multirow{2}{*}{ Scenario 9} & 1 & 892 & 45 & 156 \\
& 2 & 857 & 46 & 172 \\
\hline \multirow{2}{*}{ Scenario 10} & 1 & 862 & 45 & 204 \\
& 2 & 832 & 47 & 214 \\
\hline \multirow{2}{*}{ Scenario 11} & 1 & 803 & 44 & 153 \\
& 2 & 798 & 46 & 196 \\
\hline \multirow{2}{*}{ Scenario 12} & 1 & 792 & 46 & 175 \\
& 2 & 801 & 47 & 188 \\
\hline
\end{tabular}

Table 5 Foam-treated water mist spray tests under different scenarios.

\begin{tabular}{|c|c|c|c|c|}
\hline & Mixture ratio (\%) & Opening & Foam net & Operating pressure \\
\hline Scenario 13 & 3 & No & $x$ & 100 bar \\
\hline Scenario 14 & 3 & Yes & $x$ & 100 bar \\
\hline Scenario 15 & 3 & No & o & 100 bar \\
\hline Scenario 16 & 3 & Yes & ○ & 100 bar \\
\hline Scenario 17 & 6 & No & $x$ & 100 bar \\
\hline Scenario 18 & 6 & Yes & $x$ & 100 bar \\
\hline Scenario 19 & 6 & No & ○ & 100 bar \\
\hline Scenario 20 & 6 & Yes & ○ & $100 \mathrm{bar}$ \\
\hline Scenario 21 & 10 & No & $x$ & 100 bar \\
\hline Scenario 22 & 10 & Yes & $x$ & 100 bar \\
\hline Scenario 23 & 10 & No & ○ & 100 bar \\
\hline Scenario 24 & 10 & Yes & o & 100 bar \\
\hline
\end{tabular}

Table 6 Fire test with foam ratio of $3 \%$ under different scenarios.

\begin{tabular}{lllll}
\hline Situation model & \multicolumn{1}{l}{ Highest temperature $\left({ }^{\circ} \mathrm{C}\right)$} & Temperature after fire has been put out $\left({ }^{\circ} \mathrm{C}\right)$ & Time required to put out fire $\left({ }^{\circ} \mathrm{C}\right)$ \\
\hline \multirow{2}{*}{ Scenario 13} & 1 & 853 & 38 & 76 \\
& 2 & 846 & 36 & 99 \\
\hline \multirow{2}{*}{ Scenario 14} & 1 & 812 & 40 & 153 \\
& 2 & 821 & 38 & 123 \\
\hline \multirow{2}{*}{ Scenario 15} & 1 & 856 & 37 & 100 \\
& 2 & 863 & 36 & 99 \\
\hline \multirow{2}{*}{ Scenario 16} & 1 & 803 & 37 & 102 \\
& 2 & 796 & 38 & 95 \\
\hline
\end{tabular}




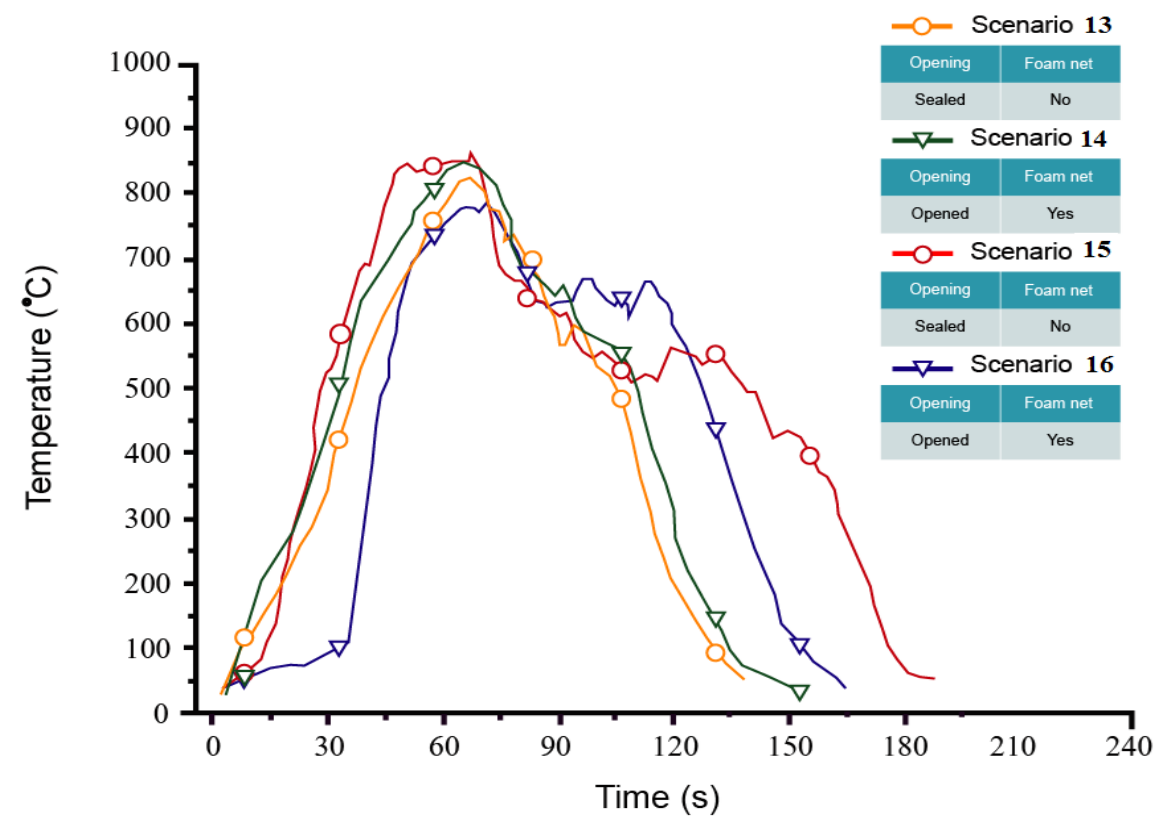

Fig. 6 Temperature variation at the sheltered fire source of the closed container (scenario 13-17).

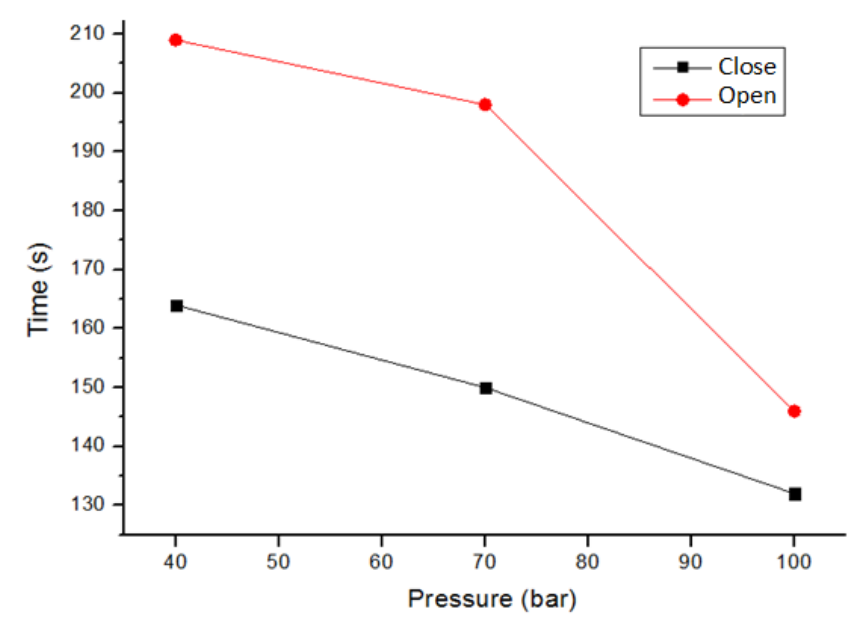

unsheltered fire source

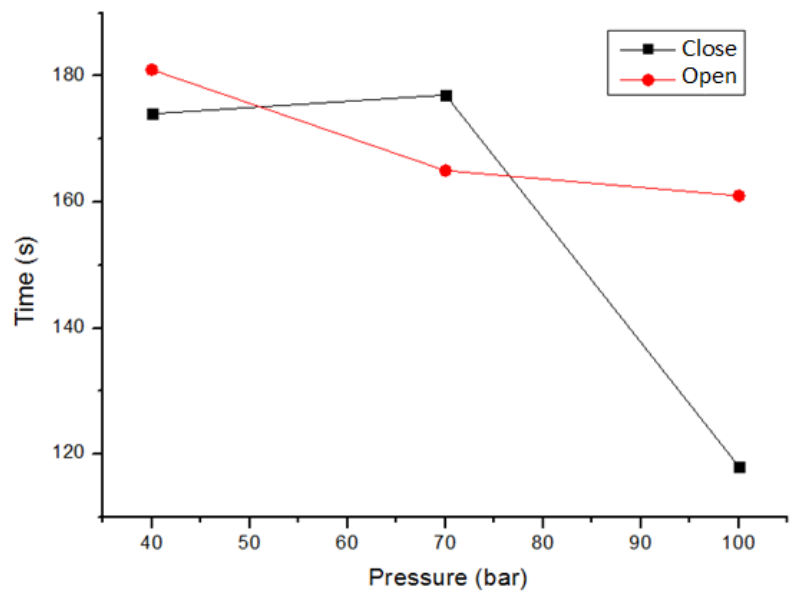

sheltered fire source

Fig. 7 Comparison with suppression time between opened container and closed container.

to about $38{ }^{\circ} \mathrm{C}$ after the fire had been put out. Fig. 7 shows comparison with suppression time between opened container and closed container.

In the scenario 14 experiment (Fig. 6), B2 oil basin was placed in the center of the container, the simulation site had an opening, foam net was not installed, and the fire was extinguished using 2 water mist spray nozzles. The water mist sprays were activated manually to put out the fire after the fire had burnt for about $60 \pm 2$ s. A total of 2 tests were conducted and the highest temperatures recorded were
812 and $821{ }^{\circ} \mathrm{C}$, respectively. During the process of putting out the fire, only the temperature at the upper part of the fire source was relatively high. The time required to put out the fire were 153 and $123 \mathrm{~s}$, respectively. The temperature at the fire scene dropped to about $39^{\circ} \mathrm{C}$ after the fire had been put out.

3.2.2 Fire Test with Foam Ratio of $6 \%$

The efficiency of the $6 \%$ foam-treated water mist spray fire protection system was assessed under several fixed parameters such as the use of B2 oil basin, the positioning of the fire source in the center of 
the container, the operating pressure of $100 \mathrm{kgf} / \mathrm{cm}^{2}$, and the flow rate of each spray nozzle at 13.5 LPM. The varying parameters included the presence or absence of foam net and opening in the simulation site (Table 5).

The test results for experiments conducted with foam ratio of $6 \%$ were listed in Table 7 . In the scenario 17 experiment (Fig. 8), B2 oil basin was placed in the center of the container, the simulation site had no opening, foam net was not installed, and the fire was extinguished using 2 water mist spray nozzles. The water mist sprays were activated manually to put out the fire after the fire had burnt for about $60 \pm 2 \mathrm{~s}$. A total of 2 tests were conducted and the highest temperatures recorded were 893 and $885^{\circ} \mathrm{C}$, respectively. During the process of putting out the fire, only the temperature at the upper part of the fire source was relatively high. The time required to put out the fire were 133 and $145 \mathrm{~s}$, respectively. The temperature at the fire scene dropped to about $38{ }^{\circ} \mathrm{C}$ after the fire had been put out.

In the scenario 18 experiment (Fig. 8), B2 oil basin was placed in the center of the container, the simulation site had an opening, foam net was not installed, and the fire was extinguished using 2 water mist spray nozzles. The water mist sprays were activated manually to put out the fire after the fire had burnt for about $60 \pm 2 \mathrm{~s}$. A total of 2 tests were conducted and the highest temperatures recorded were 867 and $871{ }^{\circ} \mathrm{C}$, respectively. During the process of putting out the fire, only the temperature at the upper part of the fire source was relatively high. The time required to put out the fire were 193 and $253 \mathrm{~s}$, respectively. The temperature at the fire scene dropped to about $37^{\circ} \mathrm{C}$ after the fire had been put out.

\subsubsection{Fire Test with Foam Ratio of $10 \%$}

The efficiency of the $10 \%$ foam-treated water mist spray fire protection system was appraised under several fixed parameters such as the use of B2 oil basin, the positioning of the fire source in the center of

Table 7 Fire test with foam ratio of $6 \%$ under different scenarios.

\begin{tabular}{lllll}
\hline Situation model & \multicolumn{1}{l}{ Highest temperature $\left({ }^{\circ} \mathrm{C}\right)$} & Temperature after fire has been put out $\left({ }^{\circ} \mathrm{C}\right)$ & Time required to put out fire $\left({ }^{\circ} \mathrm{C}\right)$ \\
\hline \multirow{2}{*}{ Scenario 17} & 1 & 893 & 38 & 133 \\
& 2 & 885 & 37 & 145 \\
\hline \multirow{2}{*}{ Scenario 18} & 1 & 867 & 39 & 193 \\
& 2 & 871 & 35 & 253 \\
\hline \multirow{2}{*}{ Scenario 19} & 1 & 854 & 36 & 126 \\
& 2 & 858 & 37 & 122 \\
\hline \multirow{2}{*}{ Scenario 20} & 1 & 846 & 36 & 95 \\
& 2 & 847 & 37 & 81 \\
\hline
\end{tabular}
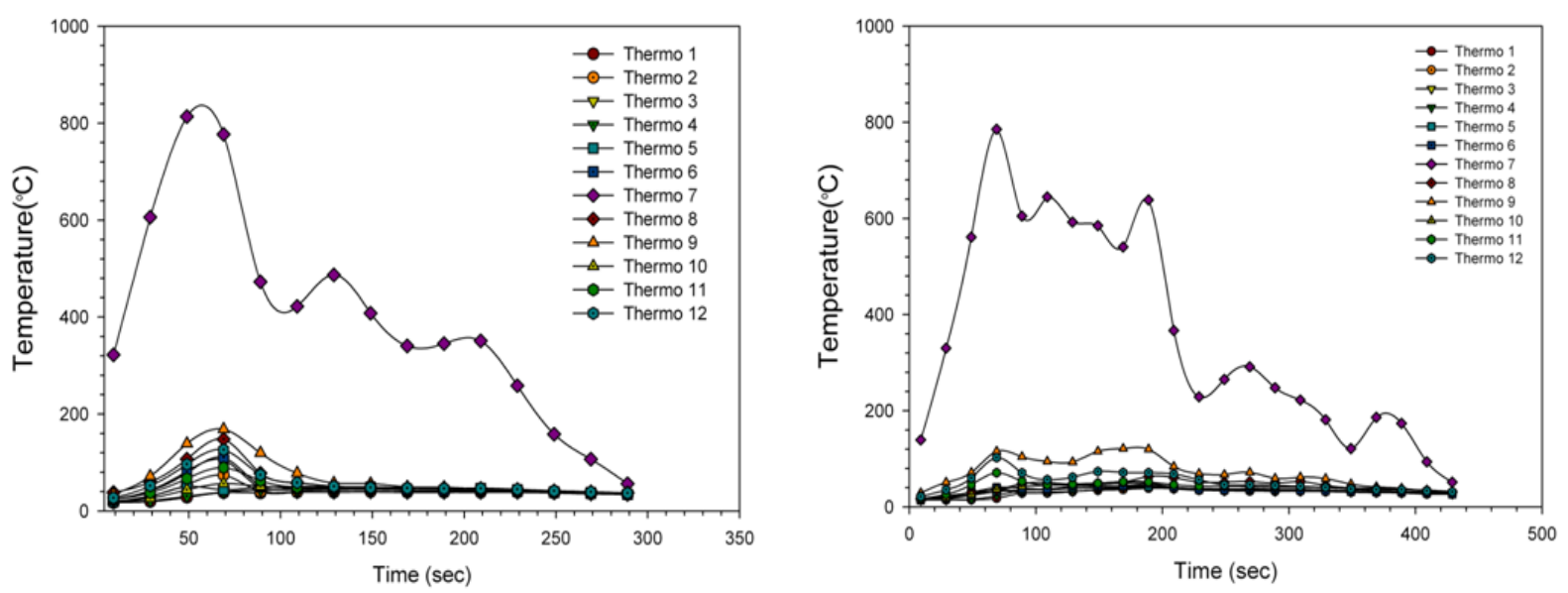

Fig. 8 Temperature variation at the sheltered fire source of the closed container (Scenario 17-18). 
the container, the operating pressure of $100 \mathrm{~kg}_{\mathrm{f}} / \mathrm{cm}^{2}$, and the flow rate of each spray nozzle at 13.5 LPM. The varying parameters included the presence or absence of foam net and opening in the simulation site (Table 5).

The test results for experiments conducted with foam ratio of $10 \%$ were listed in Table 8 . In the scenario 21 experiment (Fig. 9), B2 oil basin was placed in the center of the container, the simulation site has no opening, foam net was not installed, and the fire was extinguished using 2 water mist spray nozzles. The water mist sprays were activated manually to put out the fire after the fire had burnt for about $60 \pm 2 \mathrm{~s}$. A total of 2 tests were conducted and the highest temperatures recorded were 985 and $879{ }^{\circ} \mathrm{C}$, respectively. During the process of putting out the fire, only the temperature at the upper part of the fire source was relatively high. The time required to put out the fire were 116 and $121 \mathrm{~s}$, respectively. The temperature at the fire scene dropped to about $40{ }^{\circ} \mathrm{C}$ after the fire had been put out.

In the scenario 22 experiment (Fig. 9), B2 oil basin was placed in the center of the container, the simulation site had an opening, foam net was not installed, and the fire was extinguished using 2 water mist spray nozzles. The water mist sprays were activated manually to put out the fire after the fire had burnt for about $60 \pm 2$ s. A total of 2 tests were conducted and the highest temperatures recorded were 897 and $885{ }^{\circ} \mathrm{C}$, respectively. During the process of putting out the fire, only the temperature at the upper part of the fire source was relatively high. The time

Table 8 Fire test with foam ratio of $10 \%$ under different scenarios.

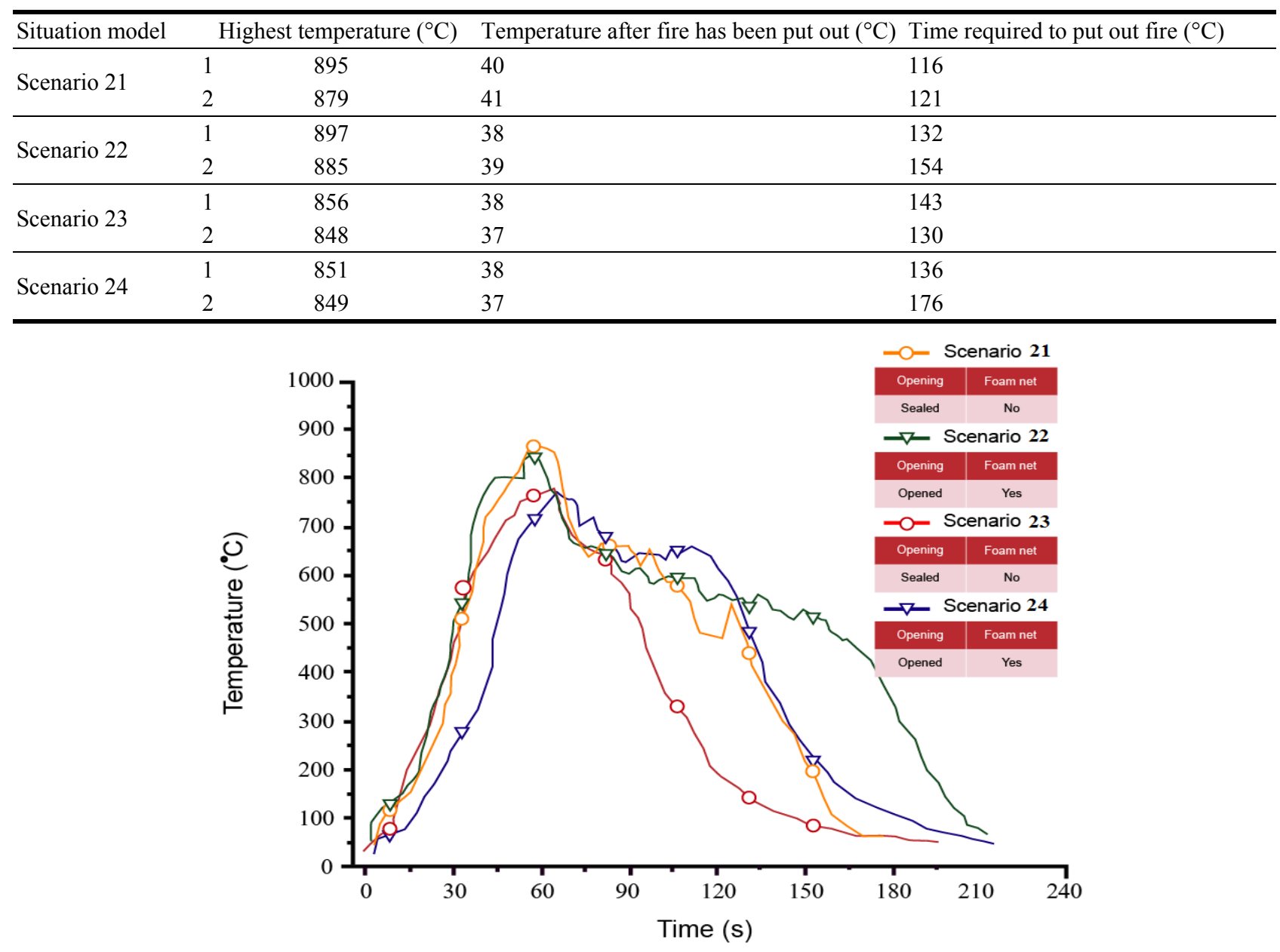

Fig. 9 Temperature variation at the sheltered fire source of the closed container (scenario 21-24). 
required to put out the fire were 132 and $164 \mathrm{~s}$, respectively. The temperature at the fire scene reduced to about $38{ }^{\circ} \mathrm{C}$ after the fire had been put out.

Fig. 10 shows comparison suppression time with foam net between without foam net water mist at sheltered fire.

\subsection{Fire Test with Foam Ratio of 3\% under Pressure of $40 \mathrm{~kg} / \mathrm{cm}^{2}$}

The efficiency of the $3 \%$ foam-treated water mist spray fire protection system under operating pressure of $40 \mathrm{~kg}_{f} / \mathrm{cm}^{2}$ was evaluated under several fixed parameters such as the use of B2 oil basin, the operating pressure of $40 \mathrm{~kg}_{\mathrm{f}} / \mathrm{cm}^{2}$, the positioning of the fire source in the center of the container, and the flow rate of each spray nozzle at 13.5 LPM. The varying parameters included the presence or absence of foam net and opening in the simulation site (Table 9).

The test results for experiments conducted with foam ratio of $3 \%$ under operating pressure of 40 $\mathrm{kg}_{\mathrm{f}} / \mathrm{cm}^{2}$ were listed in Table 10. Fig. 11 shows suppression time with pure water and $3 \%$ foam at 40 bar, and Suppression time with 40 bar and 100 bar variation at sheltered fire source of the opened container. In scenario 25, B2 oil basin was placed in the center of the container, the simulation site had no opening, foam net was not installed, and the fire was extinguished using 2 water mist spray nozzles. The water mist sprays were kicked off manually to put out the fire after the fire has burnt for about $60 \pm 2 \mathrm{~s}$. A total of 2 tests were conducted and the highest temperatures recorded were 825 and $889{ }^{\circ} \mathrm{C}$, respectively. During the process of putting out the fire, only the temperature at the upper part of the fire source was relatively high. The time required to put out the fire were 117 and $138 \mathrm{~s}$, respectively. The temperature at the fire scene dropped to about $38{ }^{\circ} \mathrm{C}$ after the fire had been put out.

In scenario 26, B2 oil basin was placed in the center of the container, the simulation site has no opening, foam net was not installed, and the fire was extinguished using 2 water mist spray nozzles. The water mist sprays were activated manually to put out the fire after the fire had burnt for about $60 \pm 2 \mathrm{~s}$. A total of 2 tests were conducted and the highest temperatures recorded were 857 and $915{ }^{\circ} \mathrm{C}$, respectively. During the process of putting out the fire,

Table 9 Fire test with foam ratio of $3 \%$ under operating pressure of $40 \mathrm{~kg}_{\mathrm{f}} / \mathrm{cm}^{2}$ and different scenarios.

\begin{tabular}{llllll}
\hline & Number of spray nozzle & Mixture ratio(\%) & Opening & Foam net & Operating pressure $\left(\mathrm{kg}_{\mathrm{f}} / \mathrm{cm}^{2}\right)$ \\
\hline Scenario 25 & 2 & 3 & Nil & Nil & 40 \\
Scenario 26 & 2 & 3 & Nil & Nil & 40 \\
\hline
\end{tabular}

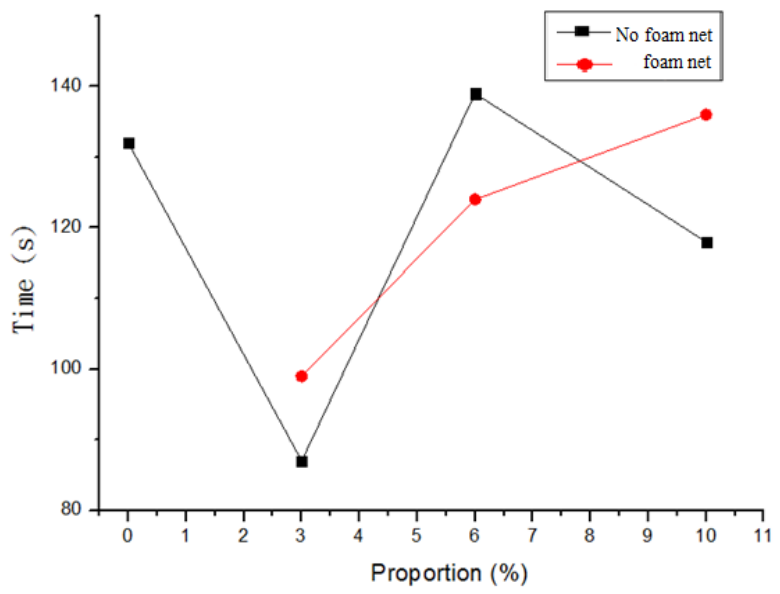

Opened container with foam

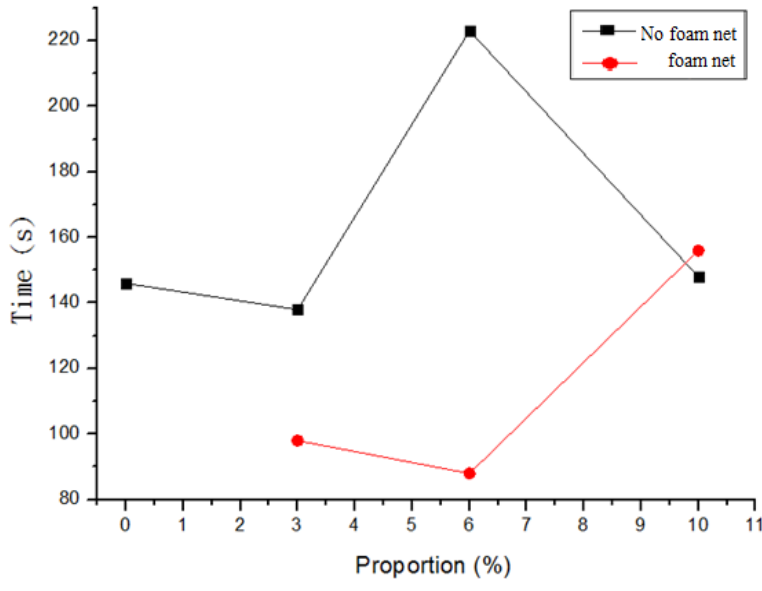

Closed container with foam

Fig. 10 Comparison suppression time with foam net between without foam net water mist at sheltered fire. 
Table 10 Results of fire test with foam ratio of $3 \%$ under operating pressure of $40 \mathrm{kgf} / \mathrm{cm}^{2}$.

\begin{tabular}{lllll}
\hline Situation model & \multicolumn{1}{l}{ Highest Temperature $\left({ }^{\circ} \mathrm{C}\right)$} & Temperature After fire has been put out $\left({ }^{\circ} \mathrm{C}\right)$ & Time required to put out fire $\left({ }^{\circ} \mathrm{C}\right)$ \\
\hline \multirow{2}{*}{ Scenario 25} & 1 & 825 & 40 & 117 \\
& 2 & 889 & 41 & 138 \\
\hline \multirow{2}{*}{ Scenario 26} & 1 & 857 & 38 & 135 \\
& 2 & 915 & 39 & 108 \\
\hline
\end{tabular}
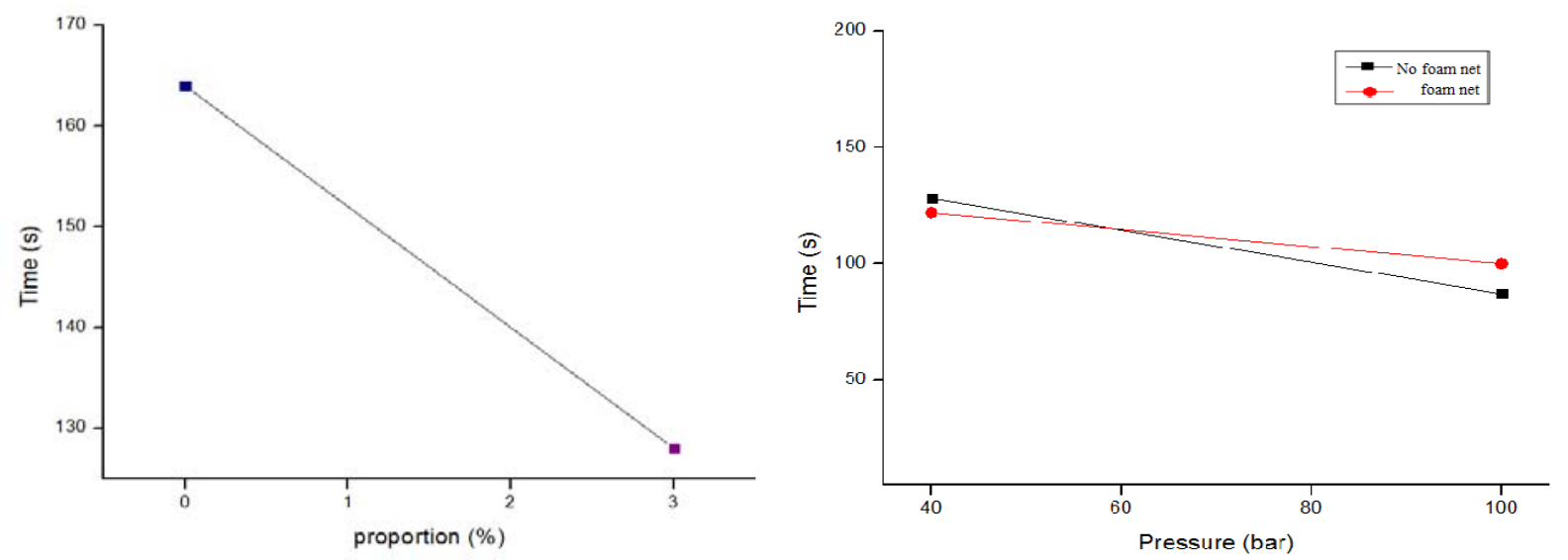

Fig. 11 Suppression time with pure water and 3\% foam at 40 bar, and Suppression time with 40 bar and 100 bar variation at sheltered fire source of the opened container (scenarios 25-26).

only the temperature at the upper part of the fire source was relatively high. The time required to put out the fire were 136 and 108 s, respectively. The temperature at the fire scene dropped to about $38{ }^{\circ} \mathrm{C}$ after the fire had been put out.

\section{Conclusions}

This study explored the fire protection efficiency of water mist spray and foam-treated water mist spray in large scale wind power generator. The conclusions below were drawn:

(1) Differences in operating pressure produce different impact forces and spraying effects during the operation of the water mist spray. The optimal mist sprays were produced when the pressure was 100 $\mathrm{kg}_{\mathrm{f}} / \mathrm{cm}^{2}$. The heat-absorbing ability of the water droplets was effectively enhanced, and the time required to put out the fire was shortened. However, the impact force at $100 \mathrm{~kg}_{\mathrm{f}} / \mathrm{cm}^{2}$ was also relatively great and can effectively impact on the fire source, along with shortening shortened the time required to put out the fire.

(2) The presence of obstructions hinders the direct impact of the mist spray on the fire source and in average an additional 2 to $3 \mathrm{~min}$ was required to put out the fire. When there were obstructions at the fire scene, the water mist spray put out the fire via air convection and the time required to put out the fire was longer than that when there were no obstructions. In such case, although the time required to put out the fire was independent of the operating pressure, the higher the operating pressure was, the less effect was the disturbance produced by the obstructions.

(3) With the addition of foam net, it was found that the foam magnification effect of the water mist spray becomes less obvious. The foam net used in this study was not suitable for the foam-treated water mist spray system studied. However, it was found that the time required to put out the fire was significantly reduced when there were both foam net and opening at the simulation site. Upon discussion, it was believed that the addition of foam net markedly reduced the impact force of the foam-treated water mist spray so that the water droplets were contained within the fire scene and not leaked out from the opening. The fire extinguishing efficiency was thus enhanced. Results 
of this study found that the effect of the foam-water ratio was linear. Regardless of the scenario, the optimal mixture ratio was $3 \%$. The line graph showed that the most unsuitable aqueous film-forming mixture ratio was $6 \%$. It was found from the experiment that without the addition of foam net, the fire control efficiency of the water mist spray under the pressure of $40 \mathrm{~kg}_{\mathrm{f}} / \mathrm{cm}^{2}$ and $100 \mathrm{~kg}_{\mathrm{f}} / \mathrm{cm}^{2}$ did not show significant difference. However, the fire control efficiency under these two pressures was enhanced with the addition of foam net.

(4) This experiment found that the main fire extinguishing mechanism of water mist spray is the cooling of a large area via water droplets. This system was very effective in bringing down the temperature. The addition of foam in water mist spray, however, impaired the effectiveness of the cooling effect although the fire control mechanism via emulsification markedly reduced the time required to put out the fire. The increase in foam magnification will considerably enhance the fire extinguishing efficiency.

\section{Acknowledgements}

The authors are indebted to Ministry of Science and Technology (MST-101-2625-M-261-001-MY3) of Taiwan, Republic of China, for financial support.

\section{References}

[1] NFPA 750. 2003. Standard for the Installation of Water Mist Fire Protection Systems. National Fire Protection Association, Quincy, MA.

[2] Braidech, M. M., Neale, J. A., Matson, A. R., Dufour, R. E. 1955. "The Mechanisms of Extinguishment of Fire by Finely Divided Water." Underwriters Laboratories, Inc. for the National Board of Fire Underwriters, New York.

[3] Mawhinney, J. R., Dlugogorski, B. Z., Kim, A. K., 1994. "A Closer Look at the Fire Extinguishing Properties of Water Mist." Fire Safety Science-Proceedings of Fourth International Symposium, Ottawa, Canada, 47-60.

[4] Richard, J,, Garo, J. P., Souil, J. M., Vantelon, J. P., 2003. "On the Flame Structure at the Base of a Pool Fire Interacting with a Water Mist." Experimental Thermal and Fluid Science, 27: 439-48.

[5] Mawhinney J. R., Solomon R., 1997. "Water Mist Fire Suppression Systems." In Fire Protection Handbook (18th ed., Section 6, Chapter 15, pp. 6/216-6/248).

[6] Xiaomeng, Z., Guangxuan, L., Bo, C., 2006. "Improvement of Water Mist's Fire-Extinguishing Efficiency with MC Additive." Fire Safety Journal: 41: $39-45$.

[7] Bruce D., Constantine P., 1995. "Interaction of a Water Mist with a Buoyant Methane Diffusion Flame." Fire Safety Journal 24: 359-81.

[8] Yang, W., Kee, R. J., 2002. "The Effect of Monodispersed Water Mists on the Structure, Burning Velocity, and Extinction Behavior of Freely Propagating, Stoichiometric, Premixed, Methane-air Flames." Combustion and Flame 130: 322-35.

[9] Aidun, A. R., ed. 1961. "Additives to Improve the Fire-Fighting Characteristics of Water." Fire Research Abstracts and Reviews 3: 91.

[10] Aidun, A. R., ed. 1961. "Additives to Improve the Fire-Fighting Characteristics of Water." Fire Research Abstracts and Reviews 3: 93.

[11] Aidun, A. R., ed. 1961. "Additives to Improve the Fire-Fighting Characteristics of Water." Fire Research Abstracts and Reviews 3:213.

[12] Grove, C. S., Aidun, A. R., 1962. "Improving the Effectiveness of Water for Fire Fighting." Syracuse University, Syracuse 10, New York.

[13] Jiann, C. Y., 2010. "Technical Support for the Study of Droplet Interactions with Hot Surfaces." National Institute of Standard and Technology. Accessed March 9, 2010. http://www.bfrl.nist.gov/866/NGP/publications/ 2B3_Final_Report.pdf.

[14] Aidun, A. R., ed. 1961. "Additives to Improve the Fire-Fighting Characteristics of Water." Fire Research Abstracts and Reviews 1: 58.

[15] Aidun, A. R., ed. 1961. "Additives to Improve the Fire-Fighting Characteristics of Water." Fire Research Abstracts and Reviews 1: 129.

[16] Aidun, A. R., ed. 1961. "Additives to Improve the Fire-Fighting Characteristics of Water." Fire Research Abstracts and Reviews 2: 71.

[17] Kim, A. K., 2000. "Fire Suppression Performance of Water Mist Systems with Additives. In: Progress in Safety Science and Technology." International Symposium on Safety Science and Technology, Beijing, China, 561-6.

[18] Finnerty, A. E., McGill, R. L., Slack, W. A., 1996. "Water-Based Halon Replacement Sprays." U.S. Army Research Laboratory, ARL-TR-1138, Aberdeen Proving Ground, MD.

[19] Zhou, X. M., Liao, G. X., Cai, B., 2006. "Improvement of Water Mist's Fire-Extinguishing Efficiency with MC Additive.” Fire Safety Journal 41: 39-45.

[20] Cong, B. H., Liao, G. X., 2009. "Experimental Studies on 
Water Mist Suppression of Liquid Fires with and without Additives." Journal of Fire Sciences 27: 101-23.

[21] McCormick, S., Clauson, M., Cross, H. 1999. "U.S.
Army Ground Vehicle Halon Replacement Programs." In Proceedings of Halon Alternatives Technical Working Conference, Albuquerque, New Mexico, 27-33.

Chen-Wei Chiu received his BS (1991) and MS (1997) in Fire Science form National Central Police University (Taiwan, ROC). He has a Ph.D. (2005) in Mechanical Engineering at National Chiao Tung University (Taiwan, ROC), and then post-doctoral study (2008) at Fire Protection Engineering Department at University of Maryland, College Park, Maryland, USA, and visiting scholar study (2014) at Fire Safety Engineering Center at University of Edinburgh, U.K. Since 2002, he has taught at the Department of Fire Safety, National Taiwan Police College, as an Associate Professor, teaching protection engineering design and fire prevention code of Taiwan. Working in fire engineering field and being an FPE (Fire Protection Engineer) at Taiwan and Japan for several years, his current researches focus on the assessment and analyses of water-based fire suppression, smoke management, as well as fundamental fire theory with a series of tests and simulations 